\title{
O vento mudou: o Estado Novo e a inclusão dos festivais da canção televisivos em sua política de integração racial $^{1}$
}

\author{
José Fernando Saroba Monteiro \\ Universidade Federal Rural do Rio de Janeiro
}

\begin{abstract}
Resumo
O Estado Novo, regime autoritário que prevaleceu em Portugal durante 41 anos, foi chefiado por António de Oliveira Salazar, entre 1933 e 1968, e Marcello Caetano, entre 1969 e 1974. Este regime, de ideais fascistas, aparentemente diferia de seus congêneres em relação à política de integração racial aplicada a suas colônias do ultramar africano, alegando sempre objetivar uma unidade multirracial e plurirracial, na qual todos seriam portugueses, estando ou não na metrópole. Entretanto, em oposição aos discursos prenunciando uma relação harmoniosa entre os povos, as guerras coloniais se deram em decorrência da negação de liberdade às colônias, mesmo motivo pelo qual a imagem do negro africano foi utilizada midiaticamente, na tentativa de demonstrar unidade e integração entre os territórios e as raças.
\end{abstract}

Palavras-chave: Estado Novo; festivais da canção; integração racial.

\begin{abstract}
The Estado Novo, authoritarian regime that prevailed in Portugal for 41 years, was headed by António de Oliveira Salazar, between 1933 and 1968, and Marcello Caetano, between 1969 and 1974. This regime, of fascist ideals, apparently differed from its counterparts in relation to the racial integration policy applied to their colonies in the African overseas, claiming to always aim at a multi and pluriracial unity, in which everyone would be Portuguese, whether or not they were in the metropolis. However, in opposition to the speeches foreshadowing a harmonious relationship between the peoples, the colonial wars occurred due to the denial of freedom to the colonies, the same reason why the image of the African black was used in media, in an attempt to demonstrate unity and integration between the territories and the races.
\end{abstract}

Keywords: Estado Novo; song festivals; racial integration.

Recebido em: 25/02/2020

Aprovado em: 08/08/2020

1 Grande parte das fontes utilizadas para a elaboração deste artigo foram conseguidas durante a permanência em Portugal, entre 2018 e 2019, possibilitada pela bolsa sanduíche concedida pela Fundação de Amparo à Pesquisa do Estado do Rio de Janeiro (Faperj), no âmbito do doutorado em História concluído em 2020 pela Universidade Federal Rural do Rio de Janeiro. 
O Estado Novo português, regime autoritário mais longo da história, de 1933 a 1974, sob o comando de António de Oliveira Salazar e, depois, de Marcello Caetano, era notadamente um regime fascista, aspecto no qual se aproxima muito de sua vizinha Espanha de Franco e de sua coetânea Itália de Mussolini, divergindo, no entanto, da Alemanha de Hitler, pois enquanto o Führer e o partido nazista se sobrepuseram ao Estado alemão, tornando-se a própria fonte do poder e do direito, o fascismo, em Portugal e na Itália, não destruíram totalmente o Estado liberal, terminando por estabelecer alianças "com outras forças e tendências conservadoras" (AZEVEDO, 1999, p. 34). Outra diferença do Estado Novo salazarista em relação ao nazismo hitleriano, ao menos aparentemente, era a política de integração racial. Em discurso de 1960, Salazar evidenciava este posicionamento:

A ideia de superioridade racial não é nossa; a da fraternidade humana, sim, bem como a da igualdade perante a lei, partindo da igualdade de méritos, como é próprio de sociedades progressivas.

Em todos esses territórios a mistura das populações auxiliaria o processo de formação de uma sociedade plurirracial; mas o mais importante, o verdadeiramente essencial estava no espírito de convivência familiar com os elementos locais; [e anunciava uma tarefa final] a independência e a igualdade dos povos integrados com seus territórios numa unidade nacional (ANTT/AOS. CO/PC-15).

Neste aspecto, Salazar apontava o Brasil como melhor exemplo de uma sociedade de consolidada integração racial:

Mais de 300 anos trabalhamos no Brasil, inspirados pelo mesmo ideal, e o que ali passou a observar-se é verdadeiramente extraordinário: O Brasil tem as portas abertas a gente de quase todo o mundo, caldeia-a na variedade dos seus elementos demográficos, absorve-a, assimila-a e não diminui em lusitanidade. Entre os países para cuja formação contribuíram raças diferentes, nenhum como ele apresenta tão completa ausência de traços racistas na legislação, na organização política, na conduta social. Ele é a maior experiência moderna de uma sociedade plurirracial, ao mesmo tempo que exemplo magnífico da transposição da civilização ocidental nos trópicos e no Continente americano (ANTT/AOS. CO/PC-15).

Sabemos, entretanto, que no Brasil houve uma convivência um tanto forçosa entre os povos que habitaram o território no período colonial. Os ameríndios viram chegar os brancos europeus e depois os negros africanos, que desembarcavam na condição de cativos, em desacordo com as condições dos outros habitantes. É conhecido o aforismo reproduzido por Charles Boxer que dizia: "O Brasil colonial foi caracterizado algumas vezes como 'um inferno para negros, um purgatório para brancos, e um paraíso para mulatos"” (BOXER, 1977, p. 102). $\mathrm{Na}$ atualidade, no Brasil, ainda que haja ampla aceitação de que a população brasileira foi 
miscigenada pela presença de muitos povos, não falta quem condene uma suposta ausência de racismo na sociedade brasileira, e até pelo contrário, assegure que há racismo.

No mesmo discurso, não obstante, concluía Salazar: "A sociedade plurirracial é portanto possível e tanto de cepa luso-americana como de base luso-asiática, segundo se vê em Goa, ou luso-africana, em Angola e Moçambique. Nada há, nada tem havido que nos leve a conclusão contrária" (ANTT/AOS. CO/PC-15).

Observamos, no entanto, que o discurso de Salazar reproduz uma acepção na qual o termo "raça" se desenvolveu como uma categoria que justificava a ascendência crescente do Ocidente sobre outros povos, considerando o que era socialmente construído como fixo e biologicamente determinado, e foi bem desenvolvido como uma maneira de reforçar o controle político e econômico sobre grupos subordinados (como na África colonial e na Alemanha nazista), ideia proveniente da teoria do darwinismo social do século XIX. Motivos que levaram a se preferir um esvaziamento do termo "raça" em detrimento de "etnia" ou "étnico", por exemplo. Ainda assim, segundo o historiador John Tosh:

A maneira como a geração anterior de historiadores escreveu sobre a expansão ocidental global deixava fortemente implícita a noção de que os povos "nativos" no polo receptor eram inferiores em suas culturas e em sua capacidade de assimilar as técnicas ocidentais; e esses estereótipos negativos serviam por sua vez para sustentar uma lisonjeira autoimagem da raça britânica — ou francesa ou alemã. Mais, recentemente, minorias dotadas de uma forte identidade étnica construíram o que se pode chamar de "discurso reverso"; elas também abraçaram o conceito de "raça", porque o termo reúne juntas a descendência biológica e a cultura num amálgama que maximiza a coesão grupal e enfatiza a distância de outros grupos (TOSH, 2011, p. 56).

Em 1967, o angolano Eduardo Nascimento venceu o Festival RTP da Canção² com "O vento mudou" (Nuno Nazareth Fernandes/João Magalhães Pereira), o que lhe conferiu o direito de representar Portugal em Viena, Áustria (coincidentemente, país de origem do Führer), tornando-se o primeiro cantor negro a se apresentar no Festival Eurovisão. Isso mostrou uma intenção nítida do regime salazarista em aparentar integração com as colônias na África. Nuno Nazareth Fernandes, compositor da canção, discorda desta afirmativa, dizendo que o convite foi feito apenas por serem conhecidos e por Eduardo Nascimento ser um bom cantor (MONTEIRO, 2019). Mas, de fato, o Estado Novo mostrava muitas preocupações,

2 O Festival RTP da Canção surge em 1964 com o intuito de integrar os portugueses ao Festival Eurovisão da Canção (Eurovision Song Contest - ESC), iniciado em 1956, inspirado no Festival de San Remo. O Festival RTP teve como primeira vencedora Oração (Francisco Nicholson/Rogério Bracinha/João Nobre), canção interpretada por António Calvário, representante do nacional-cançonetismo, vertente musical vista como favorável e difusora dos princípios salazaristas, que obteve nul points no Eurofestival, numa demonstração de descontentamento do público europeu com o governo de Salazar. 
primeiramente com a opinião pública europeia e com a imprensa, em relação ao agravamento das guerras coloniais, e também havia uma grande preocupação do governo português na manutenção das suas colônias.

Neste aspecto, em 1959, criou-se o Gabinete de Negócios Políticos (GNP), na DireçãoGeral de Administração Política e Civil do Ministério do Ultramar que, segundo nos esclarece Cláudia Castelo, reproduzindo o decreto-lei n. 42.671, de 23 de novembro de 1959, era um órgão: “[...] com extensas competências no domínio da investigação, estudo e fiscalização das políticas internas e externas relativas às colónias" (CASTELO, 2015, p. 458). Este mesmo órgão se aliou à censura na regulação das notícias publicadas na imprensa, de modo que "deviam evitar-se referências às províncias ultramarinas como partes separadas do todo nacional" e "não se podia sequer insinuar qualquer distinção entre raças", valorizando sim, “[...] a importância da miscigenação na colonização portuguesa e da 'formação do 'homem português' [...], com todas as suas implicações e consequências de não discriminação e de perfeita convivência racial"” (CASTELO, 2015, p. 461).

Pregava-se, portanto, a tolerância e a convivência racial, colocando todos como portugueses, nascidos ou não na metrópole, "portugueses de todos os continentes", como declarou Salazar no referido discurso de 1960. Entretanto, na Ásia e na África eclodiam movimentos que visavam à libertação dos domínios neocoloniais. No mesmo discurso, Salazar se referia à questão racial com certo descontentamento, devido a crescentes "explosões de violência contra o homem branco", colocando o branco como aquele que "[...] ocupou territórios livres, desbravou as terras, estabeleceu as explorações agrícolas ou industriais, financiou os empreendimentos, organizou a administração, manteve a ordem e a paz" (ANTT/AOS. CO/ PC-15); concluindo em seu discurso, ao passo que deixava claro o intuito de permanecer ocupando o território, que:

[...] essa onda de odiento racismo que se levanta contra o branco em África, se será também lá contra o amarelo amanhã, não é moral mas sobretudo não é inteligente; e que o abandono, se precipitado, de muitos territórios por parte das potências europeias se me afigura um crime mais contra o negro que se pretendia elevar do que contra o branco, mesmo que ameaçado de expulsão e despojado de todos os seus haveres (ANTT/AOS. CO/PC-15).

Não faltaram, inclusivamente, apoiantes para a política salazarista. Em agosto de 1963, Salazar fez também um discurso no Terreiro do Paço, em Lisboa, e uma multidão de 500 mil pessoas esteve presente para apoiar o estadista, não apenas da metrópole, mas também pessoas das províncias africanas prestaram apoio à presença portuguesa em África (ANTT/AOS. CO/PC-67). 
Antes disso, em 1935, chegou às mãos do governo português uma mais que peculiar carta, redigida e subscrita por alguns "deportados nativos de S. Tomé", que saudavam o "Grupo do $1^{\circ}$ Cruzeiro de Férias às Colónias", vindo da metrópole portuguesa. Na elogiosa carta, o grupo colocava Portugal como lugar de "fraternal união, de todas as raças da Nação": "Portugal engrandecido por chamar a colaborar leal e patrioticamente com a raça branca, aquelas raças nacionais que, até aqui abandonadas à sua desventurosa sorte, pretendem que lhes reconheçam o direito de serem da Nação [...]" (ANTT/AMC, Cx. 2, n. 2). A carta, portanto, mostrava claramente o interesse do grupo de negros em integrar a nação portuguesa, reforçando que o "desejo do destino patriótico" era um direito indiscutível e que havia uma "vontade inquebrantável" de serem "cidadãos de Portugal".

É difícil precisar se este era mesmo um desejo espontâneo destes homens, se foram induzidos a pensarem assim ou, ainda, se se tratava de uma tentativa de conseguir perdão a estes "23 deportados, condenados à morte". Mas, estranhamente ou não, através da carta o grupo dizia ter "esperança de que um maior contacto entre as raças nacionais, trará um maior conhecimento recíproco de resultados profícuos à fraternidade e entendimento das raças, ao progresso das mais atrasadas, a um maior bem-estar de todos", reconhecia a missão civilizadora como benéfica ao "indígena", mais do que "os bens materiais acumulados à sua volta", servindo como "indicador da qualidade e poder colonizador das Nações". E por fim, transmitiam "ao 'Povo Branco' de Portugal as saudações fraternais deste núcleo do 'Povo Negro' de Portugal que espera e quer que os seus irmãos brancos, sem zelos, compartilhem, com os seus irmãos negros, a honra insigne de serem filhos legítimos de Portugal" (ANTT/AMC, Cx. 2, n. 2).

Por esta carta temos uma visão de como era necessária aos habitantes das colônias a afirmação do pertencimento à nação portuguesa e como isso passava pela questão racial. Entretanto, eclodidas as revoltas na África, o processo parecia irreversível; basta tomarmos por base o relato de um "Elemento legionário, chegado há dias de Angola, 100\% salazarista, homem de bem", que, em 20 de março de 1961, informava "que o ambiente, em Luanda e em toda a Angola, depois destes últimos acontecimentos, é de pavor e, acima de tudo, de repulsa e indignação para com o Governo da Metrópole" (ANTT/AOS. CO/PC-76B); e continuava: "De tudo se responsabiliza o Governo, acusando-o da falta das mais rudimentares medidas de defesa dos pobres portugueses espalhados pelo interior, desarmados e sem qualquer possibilidade de defesa da mulher e dos filhos" (ANTT/AOS. CO/PC-76B); completando: "Ao mesmo tempo, em Lisboa e Porto, a opinião pública, a grande maioria das pessoas da situação e o povo em geral manifestam a sua indignação por não ser devidamente informado, no pormenor, do que se está passando em Angola. Já nem foot-ball se discute" (ANTT/AOS. CO/PC-76B).

Em 1960, chamado "ano africano", ou "ano da África: “entre janeiro e dezembro, nada menos que dezessete países tornaram-se independentes, seguidos de outros doze nos cinco anos seguintes" (FIGUEIREDO, 2012, p. 26). Por isso, neste mesmo ano, Salazar é instado 
pela ONU, através da Carta das Nações Unidas, a apresentar relatórios sobre a administração colonial, mas segundo Francisco Cádima:

Salazar subtraía-se às disposições da Carta e só em situação-limite mandava responder à ONU — como havia de acontecer em Novembro de 1967, através de Franco Nogueira - , que as colónias eram tão-só "províncias ultramarinas” por integração e multirracialismo, e que os portugueses, consideravam-se também uma "nação africana"... De nada serviria no entanto ao regime inventar estratagemas adversos aos ventos da história... (CÁDIMA, 1996, p. 64-65).

Ao mesmo tempo, chegavam à Portugal mensagens de entidades do mundo todo, expondo o desagrado com as guerras coloniais, que matavam europeus e, mais ainda, africanos, numa verdadeira carnificina que insistia em se perpetuar (ANTT/AOS. CO/UL-38A). Notadamente, "os ventos da história não mudaram" imediatamente, mas esta resposta de Salazar à ONU, dirigida em novembro de 1967, denota a inclusão do angolano Eduardo Nascimento, que meses antes representou Portugal no Festival Eurovisão, numa tentativa de o Estado Novo demonstrar tolerância racial e integração com as colônias do ultramar. Segundo Cláudia Castelo:

As orientações do GNP ecoam na "tentativa de saneamento do racismo do espaço mediático" (Cardão, 2012: 31) e na proliferação de imagens desse desejado multirracialismo nas revistas ilustradas, sobretudo no tratamento de acontecimentos da cultura de massas, como o futebol, o Festival RTP da Canção ou o Concurso Miss Portugal, e dos seus ícones: Eusébio, Eduardo Nascimento ou Riquita (CASTELO, 2015, p. 462).

Toda a concepção dos Festivais RTP, na verdade, desde o início, para além de uma inclusão na estrutura e no agrupamento de alguns países que formavam o que depois seria a União Europeia, também representava uma "[...] desejada venda da imagem externa do País, acompanhando o crescente interesse europeu por este certame" (CALLIXTO; MANGORRINHA, 2018, p. 13).

Não obstante, Eduardo Nascimento foi o primeiro cantor negro a vencer o festival e também "[...] o primeiro cantor homem negro a aparecer no Eurovisão [...]" (O'CONNOR, 2010, p. 31, tradução nossa). Houve, segundo Mauro Neves: “[...] a intenção nítida de mostrar ao público europeu em geral a filosofia da integração racial e das colônias africanas como províncias do ultramar completamente integradas à nação portuguesa" (NEVES, 2011, p. 95). E essa intenção era percebida por todos, tanto que a revista Flama ironizava a participação de Eduardo Nascimento comparando-o a Eusébio, ídolo, também negro, do futebol português, como vemos na imagem a seguir. 


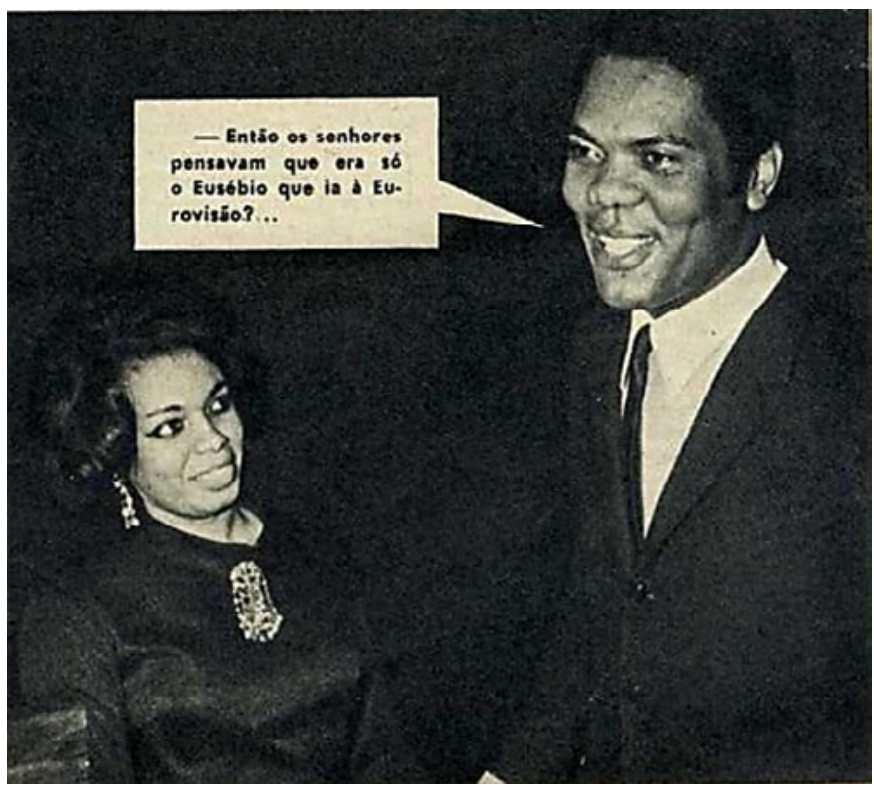

Eduardo Nascimento após a vitória no Festival RTP da Canção, 1967 (FUI AO PRÉMIO, 1967).

Paul Gambaccini et al. também comentam a participação de Eduardo Nascimento no Eurovisão:

Portugal foi um dos primeiros exemplos de emprego do politicamente correto para vencer. A sua entrada, "O Vento Mudou" foi cantada por Eduardo Nascimento de Angola, para provar que a política colonial de Portugal estava funcionando bem. Os ventos da mudança foram realmente soprando através de África, mas não o suficiente para permitir a Eduardo se tornar o primeiro africano a vencer o Eurovisão (1998, p. 42, tradução nossa).

O discurso estadonovista não era muito bem digerido pelo público europeu e igualmente pela população portuguesa, o que percebemos em uma reportagem da seção Factos e Documentos da revista Seara Nova, feita com base numa colagem de recortes de diversos jornais:

E aquela Angola invadida, que foi ontem de Portugal e hoje é e será amanhã, aquela Angola foi bem a demonstração do que representa este mundo de bárbaros, este mundo de invasores, este mundo que não respeita crianças nem mulheres, velhos e doentes, Angola foi o palco escolhido por eles para a prova do que podem e do que desejam fazer com o mundo livre. Mas Portugal estava desprevenido, mas sempre Portugal, e como Portugal de ontem o Portugal de Angola. Demonstrou e mostrou ao mundo, que a sua gente e as suas terras comandadas por Viriato ou pelo Governo actual do Senhor Presidente do Conselho, do venerando, do quase santo António de Oliveira Salazar (palmas) soube e pode manter as terras portuguesas de Angola (Seara Nova [c. 1960] apud D'ESPINEY, 1990, p. 120).

Em linhas gerais, Marcello Caetano prosseguiu com o mesmo discurso de Salazar, no qual se prenunciava uma integração racial com as províncias do ultramar. Entretanto, o 
sucessor de Salazar diferia em relação ao prosseguimento com as guerras coloniais, que julgava prejudiciais tanto para os negros africanos, quanto para os brancos da metrópole.

Em dezembro de 1968, logo depois de ascender à posição de presidente do Conselho, Marcello Caetano elaborou um extenso documento em que deixava claro seu posicionamento em relação ao "Problema do Ultramar Português". Neste documento, Caetano demonstrava reconhecer que os problemas com as províncias portuguesas na África se inseriam "numa conjuntura mundial" e apontava como principal erro "procurar a solução do fenômeno simplesmente numa acção militar". Na verdade, o governante elencava diversos fatores que, para ele, levavam ao agravamento da crise:

A circunstância de se ter procurado, até hoje, encontrar a solução do problema nacional EXCLUSIVAMENTE NUMA ACÇÃO MILITAR; a INEXISTÊNCIA DE UMA CONSCIÊNCIA NACIONAL, a conduzir a um desinteresse geral pelo problema; a FALTA DE ESTRUTURAS ADEQUADAS E DE QUADROS CAPAZES; O ABANDONO A QUE ESTÃO VOTADAS AS POPULAÇÕES DE COR, quanto a sua conquista para a causa de Portugal, e a DESCRENÇA QUE COMEÇA AAPODERARSE DAS POPULAÇÕES BRANCAS, a que se juntam as ATITUDES DESTAS PARA COM AQUELAS; são factores que, ao integrarem as linhas-de-força da nossa resposta, estão na base daquela gravidade (CAETANO apud ANTT/AMC, Cx. 12, n. 2).

Marcello Caetano chegava a anunciar diretamente "A EVOLUÇÃO NO SENTIDO DA INDEPENDÊNCIA DE ANGOLA E MOÇAMBIQUE", que de fato assumia como irreversível, e mostrava-se nitidamente cético e pessimista em relação à continuidade da guerra, declarando: "Os mortos da Guiné, de Angola e de Moçambique terão sacrificado a vida em pura perda e os jovens que, nessas terras, ficaram mutilados terão destruído o seu futuro em absoluta inutilidade". Mas, em hipótese alguma objetivava deixar o território. Para ele a resposta aos conflitos não poderia ser outra senão "PERMANECER" e permanecer através da construção de uma "PRESENÇA”, que "assente numa VERDADEIRA COMUNIDADE LUSÍADA MULTIRRACIAL", que "se projecte no futuro, para além das independências adquiridas", propondo "CHAMARMOS A NÓS AS POPULAÇÕES DE COR" e "PROVOCARMOS O AFLUXO DE POPULAÇÕES BRANCAS”, “de modo a estabelecer entre ambas um equilíbrio ajustado". Para tanto era "imperativo" a "MOBILIZAÇÃO INTEGRAL", "para que a luta seja, na verdade, de todos os portugueses, como Nação, e de cada português, como cidadão" (CAETANO apud ANTT/AMC, Cx. 12, n. 2).

No ano seguinte, Marcello Caetano promove uma visita aos territórios africanos, o primeiro chefe de Estado português, em 50 anos, a visitar o ultramar, como noticiava $O$ Século Ilustrado (A VISITA, 1969). A viagem ministerial tinha alguns "objectivos especiais", como "dar balanço às necessidades e possibilidades existentes" e "traçar in loco instruções às autoridades" (ANTT/AMC, Cx. 10, n. 10). A viagem foi aclamada como "triunfal" e, segundo a 
matéria de $O$ Século Ilustrado, abria uma "nova fase na vida política portuguesa" e acrescentava "uma nova página na História de Portugal", pois iniciava "uma abertura na vida política de todos os que se abrigam sob a protecção da bandeira portuguesa", uma nação "multirracial", calcada na "diversidade de raças", integradas ao "mundo português", que se "fundamenta em princípios humanos", inscritas "na comunidade portuguesa, sem discriminação de raças": “APENAS SUBORDINADOS AOS DESTINOS DE UM POVO QUE PROCUROU DESDE SEMPRE AFIRMAR A SUA LEGÍTIMA NACIONALIDADE DENTRO DO CONCEITO UNIVERSAL" (A VISITA, 1969, p. 30).

Durante a viagem o presidente do Conselho visitou a Guiné, Angola e Moçambique, onde declarou: "NÃO CONHECEMOS BARREIRAS DE COR, NÃO FAZEMOS DISTINÇÃO DE RAÇAS" (CAETANO apud A VISITA, 1969, p. 34). Ficava clara, no entanto, apesar da maior abertura, a continuidade com a doutrina salazarista, o que se certificava também na retórica de Marcello Caetano: "Estou aqui presente, em pessoa, como Presidente do Conselho de Ministros. Mas o espírito do Doutor Salazar veio antes de mim. E continua entre nós. Porque ele se identificou em Angola com o próprio espírito da Pátria" (CAETANO apud A VISITA, 1969, p. 34).

Caetano, portanto, espelhava-se em Salazar e alinhava-se à ideologia fascista, mas, em maio de 1975, já durante seu exílio no Brasil, apressou-se em desmentir uma notícia publicada no jornal $O$ Globo, que dava nota sobre seu "antigo entusiasmo pelos métodos nazistas de Adolf Hitler”. Em resposta, redigiu uma carta, da qual pedia a publicação e na qual declarava: "Como nunca, expressa ou implicitamente, aprovei esses métodos, só com textos falsificados, truncados ou deturpados essa pseudo-demonstração pode ser feita. [e continuava] Pelo contrário há numerosas passagens de escritos meus a condená-las" (CAETANO apud ANTT/AMC, Cx. 6, n. 2).

Dois meses depois, no mesmo jornal, procurava desmentir outra informação transmitida no programa Globo Repórter, da TV Globo, a qual afirmava que: “[...] o Governador geral da então província portuguesa dera instruções para o extermínio das populações nativas sem poupar homens, mulheres nem crianças, instruções em cujo cumprimento teriam colaborado tropas portuguesas e rodesianas" ( $O$ Globo, 3 jul. 1975, apud ANTT/AMC, Cx. 6, n. 8); o que o ex-governante negava, assegurando "que tais instruções não existem" e sobre o que ainda alegava: "Tudo indica que a notícia provenha de alguma fonte empenhada em alimentar a onda de calúnias que hoje infelizmente, no meu desgraçado País e no antigo Ultramar, não respeita nada nem ninguém" (CAETANO In: O Globo, 3 jul. 1975, apud ANTT/AMC, Cx. 6, n. 8).

São inúmeros, no entanto, os fatores que levam à derrocada do Estado Novo. A perda dos territórios na Índia mostrou certo enfraquecimento do Império no ultramar e concomitantemente decorre a eclosão das guerras na África, em três frentes, Angola (1961), Guiné (1963) e Moçambique (1964), colônias que Portugal se negava a deixar, levando António Salazar a 
proferir as célebres palavras: "Para Angola, rapidamente e em força"; em acordo com a tese integracionista do "Portugal do Minho ao Timor", mas guerras que levaram Portugal a exaurir recursos, a muitas refracções e exílios e ao descontentamento da população.

Depois da saída de Salazar, em 1968, Marcello Caetano sobe ao poder, em que se manteve até 1974, quando o Estado Novo teve o seu desfecho, com a Revolução dos Cravos, que não apenas restituiu a democracia no país, mas também despertou um exacerbado espírito de liberdade que tomou as ruas e os palcos do Festival RTP da Canção de 1975, no qual todas as canções versavam sobre o tema da Revolução, lembrando o fim do antigo regime e também das guerras coloniais.

No Festival RTP de 1977, o fim das guerras do ultramar novamente foi celebrado na canção vencedora, "Portugal no Coração" (Fernando Tordo/José Carlos Ary dos Santos), interpretada pelo grupo Os Amigos, formado especialmente para a ocasião. A canção, entretanto, mais do que recordar os terríveis acontecimentos, chegava a se desculpar "pela morte levada a tantos africanos durante os anos de guerras coloniais impetradas pela ditadura salazarista" (NEVES, 2011, p. 102), demonstrando a nova face do país, em que a democracia se consolidava, e servindo de afirmação também para este novo Portugal, renascido após o Vinte e Cinco de Abril.

\section{Referências}

ARQUIVO NACIONAL TORRE DO TOMBO/ARQUIVO MARCELLO CAETANO (ANTT/ AMC). Cx. 2, Cruzeiro de férias às colónias, Discursos, n. 2, 1923/1995.

. Cx. 6, Exílio no Brasil, documentos políticos, n. 2 e n. 8, 1923/1995.

. Cx. 10, Viagem ministerial à África, objectivos da viagem, n. 10, 1923/1995.

. Cx. 12, Presidente do Conselho, ultramar, relatórios, n. 2, 1923/1995.

ARQUIVO NACIONAL TORRE DO TOMBO/ARQUIVO OLIVEIRA SALAZAR (ANTT/ AOS). CO/PC-15, 1908/1974.

. CO/PC-67, 1908/1974.

. CO/PC-76B, 1908/1974.

. CO/UL-38A, 1908/1974.

A VISITA triunfal de Marcello Caetano à Guiné, Angola e Moçambique, O Século Ilustrado, Lisboa, n. 1634, p. 29-40, 26 abr. 1969.

AZEVEDO, Cândido de. A censura de Salazar e Marcello Caetano: imprensa, teatro, cinema, televisão, radiodifusão, livro. Lisboa: Caminho, 1999.

BOXER, Charles. Relações raciais no Império Colonial Português - 1415-1825. Porto: Afrontamento, 1977.

CÁDIMA, Francisco Rui. Salazar, Caetano e a televisão portuguesa. Lisboa: Presença, 1996. 
CALliXTO, João Carlos; MANGORRINHA, Jorge. Portugal 12 pts: Festival da Canção. Lisboa: Âncora, 2018.

CASTELO, Cláudia. A mensagem luso-tropical do colonialismo português tardio: o papel da propaganda e da censura. In: MARTINS, Moisés de Lemos. Lusofonia e interculturalidade: promessa e travessia. Ribeirão, Portugal: Húmus, 2015. p. 451-470.

CONFERÊNCIA integrada à exposição "O Ano de 1969", com participação de Simone de Oliveira, Nuno Nazareth Fernandes e mediação de Jorge Mangorrinha e Sofia Vieira Lopes. Lisboa: Biblioteca Nacional de Portugal, 28 maio 2019. Acervo pessoal do autor. 3 vídeos (33min10seg; 33min10seg; 22min02seg), son., color.

D’ESPINEY, Rui. A geração de 60 em Portugal, Sociologia: Problemas e Práticas, Lisboa, n. 8, p. 113-127, 1990.

FIGUEIREDO, Fábio Baqueiro. Entre raças, tribos e nações: os intelectuais do Centro de Estudos Angolanos, 1960-1980. 2012. 439 p. Tese (Doutorado em Estudos Étnicos e Africanos). Salvador, Universidade Federal da Bahia, 2012.

FUI AO PRÉMIO da canção "Giro-Flé-Flé-Flá”, Flama, Lisboa, p. 22-23, 3 mar. 1967. Disponível em: http://hemerotecadigital.cm-lisboa.pt/EFEMERIDES/FESTIVAL/ Imagens/1967_Flama_03Mar1967_p022-023.pdf. Acesso em: 24 set. 2020.

GAMBACCINI, Paul et al. The complete Eurovision Song Contest Companion. London: Pavilion Books, 1998.

NEVES, Mauro. O fracasso português: por que Portugal nunca conseguiu vencer o Eurovisão?, Bulletin of the Faculty of Foreign Studies, Sophia University, Tóquio, n. 46, p. 91-128, 2011.

O'CONNOR, John Kennedy. The Eurovision Song Contest: the official history. London: Carlton Books, 2010.

TOSH, John. A busca da história: objetivos, métodos e as tendências no estudo da história moderna. Petrópolis: Vozes, 2011.

\section{Minicurrículo}

José Fernando Saroba Monteiro é doutor em História pela Universidade Federal Rural do Rio de Janeiro, com período sanduíche na Faculdade de Letras da Universidade de Lisboa, pelo Centro de Literaturas e Culturas Lusófonas e Europeias. Mestre em História do Império Português (e-learning) pela Universidade Nova de Lisboa. Especialista em Teorias da Comunicação e da Imagem pela Universidade Federal do Ceará. Licenciado em História pela Universidade de Pernambuco. 